\title{
CIDEC-related familial partial lipodystrophy
}

INSERM

\section{Source}

INSERM. (1999). Orphanet: an online rare disease and orphan drug data base. CIDECrelated familial partial lipodystrophy. ORPHA:435651

A rare, genetic lipodystrophy characterized by abnormal subcutaneous fat distribution, resulting in preservation of visceral, neck and axilliary fat and absence of lower limb and femorog luteal subcutaneous fat. Additional clinical features are acanthosis nigricans, insulin-resistant type II diabetes mellitus, dyslipidemia, and hypertension, leading to pancreatitis, hepatomegaly and hepatic steatosis. 